\title{
Effect of Microwave-Assisted Extraction on the Phenolic Compounds and Antioxidant Capacity of Blackthorn Flowers
}

\author{
Vanja Lovrić, Predrag Putnik*, Danijela Bursać Kovačević, Marijana Jukić and \\ Verica Dragović-Uzelac
}

Faculty of Food Technology and Biotechnology, University of Zagreb, Pierottijeva 6, HR-10 000 Zagreb, Croatia

Received: March 7, 2016

Accepted: April 24, 2017

\begin{abstract}
Summary
This research was undertaken to investigate the influence of extraction parameters during microwave-assisted extraction on total phenolic content, total flavonoids, total hydroxycinnamic acids and total flavonols of blackthorn flowers as well as to evaluate the antioxidant capacity by two different methods (2,2-diphenyl-1-picrylhydrazyl free radical scavenging capacity and ferric reducing antioxidant power assays). The investigated extraction parameters were: solvent type and volume fraction of alcohol in solvent (50 and 70 $\%$ aqueous solutions of ethanol and methanol), extraction time $(5,15$ and $25 \mathrm{~min})$ and extraction temperature $\left(40,50\right.$ and $60^{\circ} \mathrm{C}$ ) controlled by microwave power of 100,200 and 300 W. Multivariate analysis of variance (MANOVA) was used to evaluate the differences at a $95 \%$ confidence level ( $\mathrm{p} \leq 0.05)$. The obtained results show that aqueous solution of ethanol was more appropriate solvent for extraction of phenolic compounds (total flavonoids, total hydroxycinnamic acids and total flavonols) than aqueous solution of methanol. The amount of phenolic compounds was higher in $70 \%$ aqueous solution of ethanol or methanol, while higher antioxidant capacity was observed in $50 \%$ aqueous solution of methanol. Higher temperature of extraction improved the amount of phenolic compounds and also antioxidant capacity determined by 2,2-diphenyl-1-picrylhydrazyl free radical scavenging capacity assay. Extensive duration of extraction (15- to 25-minute interval) has a significant effect only on the increase of total phenolic content, while specific phenolic compound content and antioxidant capacity were the highest when microwave extraction time of 5 min was applied.
\end{abstract}

Key words: microwave-assisted extraction, blackthorn (Prunus spinosa L.) flowers, phenolic compounds, antioxidant capacity

\section{Introduction}

Blackthorn or sloe (Prunus spinosa L.) from the family Rosaceae is a widespread wild plant growing from south-central Europe down to eastern Asia Minor and northwards to Scandinavia in open woodlands and forest margins. Nearly all parts of the plant including fruit, bark, root, leaves and flowers have been used since ancient times for the treatment of various ailments. The blackthorn flowers, which are usually processed by drying and used as tea, syrup, fresh juice or tincture to treat various diseases, may have wide potential applications in food and pharmaceutical industries $(1,2)$. Despite a great potential and the long tradition of use in folk medicine, systematic phytochemical investigations of this plant are still missing. Previous investigations refer mainly to flavonoid

\footnotetext{
*Corresponding author: Phone: +385 1460 5036; Fax: +385 1460 5072; E-mail: pputnik@alumni.uconn.edu ORCiD IDs: 0000-0001-7283-6075 (Lovrić), 0000-0003-0342-6114 (Putnik), 0000-0002-6829-6472 (Bursać Kovačević), 0000-0002-3705-8068 (Jukić), 0000-0002-4179-3727 (Dragović-Uzelac)
} 
composition of the plant. Olszewska and Wolbis (3) found complex mixture of flavonoids in blackthorn flowers: kaempferol, quercetin and their glycosides mostly with arabinose, xylose and rhamnose. Olszewska et al. (4) detected high level of flavonoids in blackthorn from the Polish area (about $3.8 \%$ as glycosides and $2.7 \%$ as aglycones), while Tamas (5) revealed that Romanian population of this plant contained around $1.2 \%$ flavonoid aglycones. Besides flavonoids, Olszewska and Wolbiś (6) have studied phenolic acids and found that $p$-hydroxybenzoic acid is the dominant fraction of phenolic acids in the flowers of blackthorn, while Kolodziej et al. (7) isolated A-type proanthocyanidins from this plant.

Due to the presence of phenolic compounds, blackthorn flowers have health beneficial effect: they may eliminate harmful products and excess of sodium ions from metabolism, may help in cleaning of blood and lungs, strengthening of stomach and reducing the permeability of blood vessels, and could also be used as natural laxatives and diuretics $(1,8)$. Phenolic compounds from plants tend to be thermally unstable, and lost during processing (9). Considering a high biological potential of blackthorn flowers and the great structural diversity of phenolic compounds, it is crucial to choose an effective extraction method to ensure minimal degradation and thus obtain the highest yield of phenolic compounds $(10,11)$. Apart from the conventional methods $(12,13)$, recently there has been a growing interest in using novel extraction techniques including microwave-assisted extraction (MAE).

MAE and other advanced techniques (14-17) are widely used for extraction of phenolic components of plant material (18-20). Compared to conventional techniques of extraction, the advantages of MAE are: reduced use of solvents, time reduction and improved extraction yield (21).

The improvement of extraction yield in MAE is attributed to its effect of heating, which happens because of dipole rotation and conduction of ions presented in the solute and the solvent. As a result of these processes, hydrogen bonds are disrupted, which improves the solvent penetration into the matrix, allowing the extraction of components (22). Aside from the applied method, the extraction of phenolics is affected by many factors such as the type and polarity of the used solvent, physical and chemical characteristics of the samples, time and temperature of extraction, sample-to-solvent ratio and the characteristics of the matrix including particle size (23-25). Furthermore, the efficiency of the extraction of the phenolics by MAE is affected by the microwave power which controls the set temperature $(25,26)$.

The proper selection of extraction solvents depends on the penetration of the solvent into the matrix, the solubility of the target compound, the interaction between the solvent and the plant matrix and the capability of the solvent to heat up as a result of absorption of microwave energy.

Theoretically, when the solvent has high dielectric constant and dielectric loss constant, the capacity of the solvent to absorb the microwave energy is high $(25,27)$. Depending on the values of these constants, the most suitable solvents for the MAE of plant bioactive compounds are water, ethanol, acetone, methanol, propan-2-ol and acetonitrile (28).
Additionally, the efficiency of the MAE depends on the temperature and time of extraction. The increase of temperature and extraction time results in the improved extraction yield, but high temperatures and prolonged extraction time may cause the degradation of the thermolabile bioactive compounds $(29,30)$. In order to avoid degradation and oxidation, it is crucial to select properly the extraction temperature and time of MAE, which is quite short in comparison with conventional techniques (25). Dragović-Uzelac et al. (24) concluded that extending the extraction time from 3 to 9 min increased the extraction yield of sage extracts and at 9 min the maximum extraction was achieved.

There is only little research of phenolic compounds from the blackthorn flowers that focused mainly on the individual groups of phenolic compounds, but information regarding systematic phenolic composition and antioxidant capacity is still missing. In addition, there is lack of information about applying new extraction techniques that are increasingly applied with the ultimate goal of reducing pollution. Therefore, the goal of the present research is to investigate the effect of extraction parameters on total phenolic content (TPC), total flavonoids (TF), total hydroxycinnamic acids (THC) and total flavonols from dried blackthorn flowers by MAE, as well as to determine the antioxidant capacity of the obtained extracts by two different assays (2,2-diphenyl-1-picrylhydrazyl free radical scavenging capacity (DPPH) and ferric reducing antioxidant power (FRAP)). The investigated factors were: solvent type and volume fraction of ethanol and methanol in aqueous solutions (50 and $70 \%$ ), extraction time of 5,15 and $25 \mathrm{~min}$ and extraction temperature of 40,50 and $60{ }^{\circ} \mathrm{C}$ controlled by microwave power of 100, 200 and 300 $\mathrm{W}$.

\section{Materials and Methods}

\section{Chemicals and standards}

Methanol was purchased from Macron Fine Chemicals $^{\mathrm{TM}}$ (Avantor, Oslo, Norway). Ethanol, ascorbic acid and iron(III) chloride hexahydrate were obtained from Gram-Mol (Zagreb, Croatia). Aluminium chloride, Folin-Ciocalteu reagent and sodium acetate trihydrate were obtained from Kemika (Zagreb, Croatia) and anhydrous sodium carbonate was purchased from T.T.T. (Sveta Nedjelja, Croatia). Quercetin-3-O-galactoside was purchased from Extrasynthese (Lyon, France). The 2,2-diphenyl-1-picrylhydrazyl (DPPH) radical, ( \pm -6-hydroxy-2,5,7,8-tetramethylchromane-2-carboxylic acid (Trolox), 2,4,6-tripyridyl-s-triazine (TPTZ) and caffeic acid were obtained from Sigma-Aldrich (Buchs, Switzerland). Hydrochloric acid was obtained from Carlo Erba Reagents S.r.l. (Val-de-Reuil, France) and potassium acetate was obtained from VWR Chemicals (Radnor, PA, USA).

\section{Plant material}

Dried flowers of the wild blackthorn were purchased from a local producer (Suban Ltd., Strmec, Croatia) and the botanical identification was carried out in cooperation with Faculty of Agriculture, University of Zagreb, Za- 
greb, Croatia. Before analyses, the flowers were milled to a fine powder using electrical coffee and spice grinder Dolcevita CG1 (Imetec, Azzano San Paolo, Italy). To prevent the decrease of target phenolic compounds, the milling process was paused every 15 seconds for 10 seconds. The particle size and the size distribution of the sample were determined by laser particle size analyser (Mastersizer 2000; Malvern Instruments, Malvern, Worcestershire, UK). The diameter of $90 \%$ of the particles was smaller than $349 \mu \mathrm{m}$. Finer particles of the sample enhance penetration of the microwaves (25) and increase the contact surface area of the sample and the solvent material, which can result in the improvement of extraction efficiency $(25,26)$.

\section{Microwave-assisted extraction of blackthorn flowers}

Microwave-assisted extraction (MAE) experiments were performed using a single-mode focused microwave reactor Start S Microwave Labstation for Synthesis (Milestone, S.r.l., Sorisole, Italy). A mass of $(500 \pm 0.1) \mathrm{mg}$ of milled blackthorn flowers was mixed with $20 \mathrm{~mL}$ of solvent (50 and $70 \%$ aqueous solution of ethanol or methanol) and placed into a round-bottom flask. Extracts were constantly stirred (80\% level) using a magnetic stirrer to assure homogenisation of the extracts and the constant temperature during MAE. The default microwave power ranged from 100 to $300 \mathrm{~W}$ and it served to maintain the set temperature $\left(100 \mathrm{~W}\right.$ at $40{ }^{\circ} \mathrm{C}, 200 \mathrm{~W}$ at $50{ }^{\circ} \mathrm{C}, 300 \mathrm{~W}$ at $\left.60{ }^{\circ} \mathrm{C}\right)$. After the extraction, the extracts were transferred to 25 -mL flasks, made up with solvent used for the extraction and then centrifuged (Rotofix 32; Hettich, Germany) at $5000 \times g$ for $10 \mathrm{~min}$. The supernatant was collected, flushed with inert nitrogen, and stored at $-60^{\circ} \mathrm{C}$ until further use. All the MAE extracts were prepared in parallel and used for the spectrophotometric determination of total phenolic content, total flavonoids, total hydroxycinnamic acids, total flavonols and antioxidant capacity (DPPH and FRAP).

\section{Determination of total phenolic content}

Total phenolic content (TPC) of blackthorn flower extracts was determined using Folin-Ciocalteu method previously reported by Shortle et al. (31) with a slight modification. A volume of $100 \mu \mathrm{L}$ of extract (5-fold diluted) was mixed with $200 \mu \mathrm{L}$ of Folin-Ciocalteu reagent and $2 \mathrm{~mL}$ of distilled water, and after $3 \mathrm{~min} 1 \mathrm{~mL}$ of $20 \% \mathrm{Na}_{2} \mathrm{CO}_{3}$ was added. This mixture was incubated at $50{ }^{\circ} \mathrm{C}$ for 25 min. The absorbance was measured at $765 \mathrm{~nm}$ using a spectrophotometer (model UV-1600PC; VWR International, Leuven, Belgium). The blank contained $100 \mu \mathrm{L}$ of the solvent used for extraction instead of the extract. The TPC was calculated according to the gallic acid standard calibration curve:

$$
\mathrm{y}=0.0035 \mathrm{x}, \mathrm{R}^{2}=0.9995
$$

and expressed in $\mathrm{mg}$ of gallic acid equivalents (GAE) per $\mathrm{g}$ of dried blackthorn flowers.

\section{Determination of total flavonoids}

Total flavonoids (TF) of blackthorn flower extracts were measured using the aluminium chloride colourimet- ric method previously reported by Chang et al. (32) with some modifications. A volume of $500 \mu \mathrm{L}$ of plant extract (2.5-fold diluted) was mixed with $1.5 \mathrm{~mL}$ of $96 \%$ ethanol, $0.1 \mathrm{~mL}$ of $10 \%$ aluminium chloride (by mass per volume), $0.1 \mathrm{~mL}$ of $1 \mathrm{M}$ potassium acetate and $2.8 \mathrm{~mL}$ of distilled water, and kept at room temperature for $30 \mathrm{~min}$. The absorbance was measured at $415 \mathrm{~nm}$. The blank contained $500 \mu \mathrm{L}$ of the solvent used for extraction instead of the extract, and $0.1 \mathrm{~mL}$ distilled water instead of $10 \%$ aluminium chloride. The TF were calculated according to the quercetin standard calibration curve:

$$
y=0.0699 x+0.0002, R^{2}=0.9977
$$

and expressed in $\mathrm{mg}$ of quercetin equivalents (QE) per $\mathrm{g}$ of dried blackthorn flowers.

\section{Determination of total hydroxycinnamic acids and total flavonols}

Total hydroxycinnamic acids (THC) and total flavonols of the blackthorn flower extracts were analysed using a method described by Howard et al. (33). A volume of $250 \mu \mathrm{L}$ (2.5-fold diluted) of each extract was mixed with $0.25 \mathrm{~mL}$ of $1 \mathrm{~g} / \mathrm{L}$ of $\mathrm{HCl}$ and $4.55 \mathrm{~mL}$ of $2 \mathrm{~g} / \mathrm{L}$ of $\mathrm{HCl}$. The absorbance of the mixture was measured at $320 \mathrm{~nm}$ (THC) and $360 \mathrm{~nm}$ (total flavonols). The blank contained $250 \mu \mathrm{L}$ of the solvent used for the extraction instead of the extract. THC were calculated according to the caffeic acid standard calibration curve:

$$
y=0.0047 x+0.0231, R^{2}=0.9998
$$

and total flavonols were calculated according to the quercetin standard calibration curve:

$$
y=0.0031 x, R^{2}=0.9975
$$

Results were expressed in mg of caffeic acid equivalents (CAE) or quercetin equivalents (QE) respectively per $\mathrm{g}$ of dried blackthorn flowers.

\section{2,2-Diphenyl-1-picrylhydrazyl free radical scavenging capacity}

The antioxidant capacity of the blackthorn flower extracts was determined by DPPH free radical scavenging method according to the procedure described by Nuengchamnong et al. (34). A volume of $750 \mu \mathrm{L}$ of the sample (25-fold diluted) was mixed with $1.5 \mathrm{~mL}$ of $0.2 \mathrm{mM} \mathrm{DPPH}$. The absorbance of the mixtures was measured at $517 \mathrm{~nm}$ after $30 \mathrm{~min}$ of incubation at $37^{\circ} \mathrm{C}$. The blank contained $750 \mu \mathrm{L}$ of methanol instead of the extract. DPPH capacity was calculated according to the Trolox dissolved in methanol as standard calibration curve:

$$
y=-0.008 x+1.347, R^{2}=0.9948
$$

and expressed in $\mu \mathrm{mol}$ of Trolox equivalents (TE) per $g$ of dried blackthorn flowers.

\section{Ferric reducing antioxidant power}

The antioxidant capacity of the blackthorn flower extract was also determined using a modified ferric reducing antioxidant power (FRAP) method (31). The FRAP 
reagent was prepared immediately prior to the determination by mixing $0.3 \mathrm{M}$ acetate buffer ( $\mathrm{pH}=3.6)$, 2,4,6-tripyridyl-s-triazine (TPTZ) solution and $20 \mathrm{mM} \mathrm{FeCl}_{3} \cdot 6 \mathrm{H}_{2} \mathrm{O}$ solution in the ratio of 10:1:1 (by volume), respectively. All reagents including standards were incubated at $37^{\circ} \mathrm{C}$ prior to analyses. The extracts $(300 \mu \mathrm{L}, 50$-fold diluted) were mixed with $2.25 \mathrm{~mL}$ of FRAP reagent and incubated at $37^{\circ} \mathrm{C}$ for $10 \mathrm{~min}$. The absorbance was measured at 593 $\mathrm{nm}$. The blank contained $300 \mu \mathrm{L}$ of the solvent used for extraction instead of the extract. FRAP values were calculated according to a standard curve of ascorbic acid:

$$
y=0.0353 x-0.1021, R^{2}=0.9896
$$

and the results were expressed in $\mathrm{mg}$ of ascorbic acid equivalents (AAE) per $g$ of dried blackthorn flowers. All results were multiplied by 2 , since ascorbic acid can accept two electrons while the reduction from $\mathrm{Fe}^{3+}$ to $\mathrm{Fe}^{2+}$ ions requires one (35).

\section{Experimental methodology and statistical analysis}

Full factorial randomised design $(N=72)$ was implemented in order to estimate the effect of the different variables on the results. Dependent variables were: TPC, TF, THC, total flavonols and antioxidant capacity (FRAP and $\mathrm{DPPH})$. Independent variables were: solvent type (ethanol and methanol), solvent volume fractions (50 and $70 \%$ aqueous solution), extraction temperature (40,50 and 60 $\left.{ }^{\circ} \mathrm{C}\right)$ and extraction time (5, 15 and $\left.25 \mathrm{~min}\right)$. Multivariate analysis of variance (MANOVA) was used to evaluate the differences at a $95 \%$ confidence level $(p \leq 0.05)$. All data were analysed by the IBM SPSS Statistics (36) and Statgraphics Centurion (37).

\section{Results and Discussion}

The amount of TPC expressed as GAE extracted from flowers ranges from $(45.2 \pm 1.2)$ to $(63.7 \pm 2.9) \mathrm{mg} / \mathrm{g}$ (Table 1$)$, while average amount of TPC was $54.1 \mathrm{mg} / \mathrm{g}$ in all extracts of blackthorn flowers (Table 2). Blackthorn flowers contain a higher level of phenolic compounds than other plant species. Olszewska and Kwapisz (38) found slightly lower amount of TPC (expressed as GAE per dry mass) in extracts of Prunus padus L. flowers (Rosaceae), obtained with Soxhlet, which range from 4.92 to $5.11 \%$. Dragović-Uzelac et al. (24) studied TPC in sage extracts obtained by MAE and found that TPC (expressed as rosmarinic acid equivalents) was $(23.5 \pm 1.0)-(52.1 \pm 1.0) \mathrm{mg} / \mathrm{g}$. Ince et al. (39) found that TPC in nettle extracts expressed as GAE obtained by MAE and ultrasound-assisted extraction was $(14.4 \pm 0.9)-(25.7 \pm 0.5) \mathrm{mg} / \mathrm{g}$. Furthermore, flavonols were a predominant group of phenolic compounds in the extracts of blackthorn flowers. The average amount of total flavonols as QE in all extracts of blackthorn flowers was $20.6 \mathrm{mg} / \mathrm{g}$, then THC (as CAE) $20.2 \mathrm{mg} / \mathrm{g}$ and TF (as QE) $13.84 \mathrm{mg} / \mathrm{g}$ (Table 2). Recent data of the amount of total flavonols or other phenolic compounds from blackthorn flowers are missing. The average amount of DPPH (as TE) of all extracts of blackthorn flowers was $190.4 \mu \mathrm{mol} / \mathrm{g}$ $(3826.4 \mu \mathrm{mol} / \mathrm{L})$ and $98.1 \mathrm{mg} / \mathrm{g}(1971.0 \mathrm{mg} / \mathrm{L})$ of FRAP as AAE (Table 2), which was slightly higher than in other plants. Shortle et al. (31) found that antioxidant capacity (expressed as AAE) of hawthorn leaves and flowers ranged from $(232.4 \pm 10.2)$ to $(1631.0 \pm 9.0) \mathrm{mg} / \mathrm{L}$, depending on the selected extraction technique.

\section{Influence of solvent type and volume fraction of alcohol in the extraction solvent}

One of the most important parameters in the extraction of phenolic compounds from plant material is the selection of the most appropriate solvent, because phenolic yield is directly attributed to the solubility of the phenolic compounds in the solvent. From the results shown in Table 2, it is clear that the aqueous solution of ethanol was more efficient solvent than the aqueous solution of methanol in extracting TPC, TF and total flavonols from the extracts of blackthorn flowers, regardless of the volume fraction in the solution. Higher antioxidant capacity of the extracts was also evaluated in ethanol solutions, although ethanol has lower dielectric constant (24.3) and dielectric loss constant (2.500) than methanol (32.6 and 6.400 , respectively) (25), which can lead to a conclusion that differences in these constants do not differ enough to cause major distinctions in extraction yield. Furthermore, the extraction of phenolics depends on many other factors (the interactions between the sample and the solvent, the solubility of the sample in the solvent, the hydrophobicity and acid-base properties of the sample and solvent, etc.). Wang and Halliwell (40) also reported that aqueous solution of ethanol was preferable to aqueous solution of acetone and methanol in the extraction of tea flavonoids. Contrary to the above, Drużyńska et al. (41) found that aqueous methanol was a better solvent than water, aqueous acetone or ethanol in the extraction of TPC from green tea. Solvent type had no influence only on the amount of the THC ( $>0.05)$. Similar amount of THC was determined in all extracts regardless of the type of solvent used for extraction.

Furthermore, it was shown that $70 \%$ aqueous solutions of alcohol (both ethanol and methanol) proved to be more efficient than $50 \%$ aqueous solutions of alcohol for the extraction of TF, THC and total flavonols. This could be explained by the fact that higher water level in the solvent increases the polarity of the mixture to a level which is no longer suitable for extraction, resulting in reduced extraction yield (25). Song et al. (42) found that 60-80\% aqueous solution of ethanol was optimal in extracting total phenolic compounds from sweet potato leaves. Zhang et al. (43) and Thoo et al. (44) also found that ethanol levels of 70 and $60 \%$, respectively, were optimal for extraction of phenolics from plants.

On the contrary, the highest antioxidant capacity (DPPH and FRAP values) was observed with $50 \%$ aqueous solution of alcohol, which means that antioxidant capacity depends not only on the phenolic composition, but also on the presence of other bioactive compounds such as vitamins (tocopherols, ascorbic acid), the synergic effect and interactions among these compounds (45).

Regardless of the solvent, level of alcohol in aqueous solution (50 and $70 \%$ ) did not affect only the TPC, which could be explained by the fact that some other compounds, not included in this study, contribute to the amount of TPC in blackthorn flowers. 
Table 1. Mass fraction of total phenolic content, total flavonoids, total flavonols, total hydroxycinnamic acids in and antioxidant capacity of the extracts obtained by microwave-assisted extraction using various solvents at different temperatures and time

\begin{tabular}{|c|c|c|c|c|c|c|c|c|c|c|}
\hline \multirow{2}{*}{\multicolumn{2}{|c|}{$\frac{\varphi \text { (solvent) }}{\%}$}} & \multirow{2}{*}{$\frac{\mathrm{T}}{{ }^{\circ} \mathrm{C}}$} & \multirow{2}{*}{$\frac{t}{\min }$} & \multirow{2}{*}{$N$} & \multirow{2}{*}{$\frac{w(\text { TPC as GAE })}{\mathrm{mg} / \mathrm{g}}$} & \multirow{2}{*}{$\frac{w(\mathrm{TF} \text { as } \mathrm{QE})}{\mathrm{mg} / \mathrm{g}}$} & \multirow{2}{*}{$\frac{w \text { (TFLA as QE) }}{\mathrm{mg} / \mathrm{g}}$} & \multirow{2}{*}{$\frac{w \text { (THC as CAE) }}{\mathrm{mg} / \mathrm{g}}$} & \multirow{2}{*}{$\frac{\mathrm{DPPH} \text { (as TE) }}{\mu \mathrm{mol} / \mathrm{g}}$} & \multirow{2}{*}{$\frac{\mathrm{FRAP}(\text { as AAE) }}{\mathrm{mg} / \mathrm{g}}$} \\
\hline & & & & & & & & & & \\
\hline \multirow{18}{*}{$\begin{array}{l}\vec{O} \\
\stackrel{\Xi}{\Xi} \\
\stackrel{ \pm}{ \pm 1}\end{array}$} & \multirow{9}{*}{50} & \multirow{3}{*}{40} & 5 & 2 & $55.5 \pm 5.8$ & $14.4 \pm 0.8$ & $20.2 \pm 1.2$ & $17.7 \pm 0.2$ & $187.5 \pm 3.8$ & $96.6 \pm 13.0$ \\
\hline & & & 15 & 2 & $55.3 \pm 7.3$ & $13.2 \pm 0.3$ & $19.9 \pm 0.8$ & $19.1 \pm 0.6$ & $190.9 \pm 0.9$ & $103.2 \pm 0.8$ \\
\hline & & & 25 & 2 & $50.0 \pm 0.5$ & $13.2 \pm 0.2$ & $19.8 \pm 0.0$ & $17.7 \pm 1.3$ & $180.5 \pm 17.2$ & $85.5 \pm 7.1$ \\
\hline & & \multirow{3}{*}{50} & 5 & 2 & $52.8 \pm 0.1$ & $12.6 \pm 1.0$ & $20.1 \pm 0.3$ & $18.3 \pm 0.8$ & $191.3 \pm 0.2$ & $95.3 \pm 4.0$ \\
\hline & & & 15 & 2 & $63.3 \pm 9.1$ & $14.1 \pm 0.1$ & $19.4 \pm 1.3$ & $18.7 \pm 0.4$ & $190.6 \pm 0.6$ & $95.8 \pm 8.3$ \\
\hline & & & 25 & 2 & $58.9 \pm 12.2$ & $15.4 \pm 1.7$ & $20.2 \pm 0.7$ & $18.9 \pm 0.3$ & $191.8 \pm 2.1$ & $106.7 \pm 2.7$ \\
\hline & & \multirow{3}{*}{60} & 5 & 2 & $56.0 \pm 6.2$ & $14.3 \pm 0.3$ & $20.7 \pm 0.2$ & $19.2 \pm 1.1$ & $192.7 \pm 2.8$ & $69.2 \pm 6.6$ \\
\hline & & & 15 & 2 & $56.8 \pm 2.4$ & $13.4 \pm 1.0$ & $20.9 \pm 1.3$ & $17.9 \pm 0.2$ & $191.2 \pm 0.6$ & $103.6 \pm 0.3$ \\
\hline & & & 25 & 2 & $51.4 \pm 0.3$ & $15.3 \pm 0.1$ & $20.9 \pm 0.5$ & $19.2 \pm 0.8$ & $193.3 \pm 1.1$ & $99.7 \pm 3.9$ \\
\hline & \multirow{9}{*}{70} & \multirow{3}{*}{40} & 5 & 2 & $46.1 \pm 1.3$ & $15.0 \pm 0.8$ & $21.8 \pm 0.8$ & $22.2 \pm 0.3$ & $187.6 \pm 3.9$ & $85.5 \pm 8.4$ \\
\hline & & & 15 & 2 & $47.8 \pm 4.1$ & $13.4 \pm 0.2$ & $22.2 \pm 0.5$ & $21.2 \pm 0.4$ & $190.7 \pm 3.0$ & $95.1 \pm 3.8$ \\
\hline & & & 25 & 2 & $58.4 \pm 0.4$ & $15.2 \pm 0.3$ & $22.4 \pm 0.2$ & $20.0 \pm 0.1$ & $188.2 \pm 1.0$ & $91.5 \pm 11.6$ \\
\hline & & \multirow{3}{*}{50} & 5 & 2 & $47.0 \pm 2.9$ & $14.7 \pm 0.3$ & $20.3 \pm 2.8$ & $21.7 \pm 0.1$ & $190.3 \pm 0.2$ & $87.8 \pm 3.8$ \\
\hline & & & 15 & 2 & $58.1 \pm 6.0$ & $14.1 \pm 2.5$ & $22.8 \pm 1.4$ & $22.3 \pm 1.5$ & $192.0 \pm 1.8$ & $95.3 \pm 5.1$ \\
\hline & & & 25 & 2 & $63.7 \pm 2.9$ & $15.6 \pm 0.5$ & $22.2 \pm 0.3$ & $22.5 \pm 0.4$ & $189.2 \pm 0.3$ & $101.4 \pm 3.8$ \\
\hline & & \multirow{3}{*}{60} & 5 & 2 & $61.6 \pm 4.2$ & $15.5 \pm 1.0$ & $22.7 \pm 0.1$ & $22.4 \pm 1.9$ & $190.3 \pm 1.7$ & $94.4 \pm 1.6$ \\
\hline & & & 15 & 2 & $62.9 \pm 6.5$ & $15.0 \pm 0.3$ & $23.0 \pm 0.8$ & $21.6 \pm 0.5$ & $193.3 \pm 1.3$ & $100.0 \pm 4.3$ \\
\hline & & & 25 & 2 & $61.7 \pm 12.8$ & $15.1 \pm 0.7$ & $23.8 \pm 0.3$ & $22.0 \pm 1.0$ & $191.3 \pm 0.8$ & $94.4 \pm 7.3$ \\
\hline \multirow{18}{*}{$\begin{array}{l}\overrightarrow{0} \\
\text { है } \\
\text { 总 } \\
\sum\end{array}$} & \multirow{9}{*}{50} & \multirow{3}{*}{40} & 5 & 2 & $49.0 \pm 1.6$ & $13.0 \pm 0.1$ & $17.6 \pm 0.4$ & $19.5 \pm 1.0$ & $196.7 \pm 8.9$ & $121.3 \pm 6.5$ \\
\hline & & & 15 & 2 & $52.2 \pm 6.4$ & $12.7 \pm 1.0$ & $19.0 \pm 0.4$ & $18.6 \pm 0.4$ & $198.1 \pm 1.8$ & $95.7 \pm 2.5$ \\
\hline & & & 25 & 2 & $49.5 \pm 4.1$ & $11.9 \pm 0.1$ & $17.9 \pm 0.6$ & $19.3 \pm 0.1$ & $193.1 \pm 1.3$ & $102.1 \pm 11.4$ \\
\hline & & \multirow{3}{*}{50} & 5 & 2 & $52.3 \pm 1.5$ & $13.4 \pm 0.6$ & $18.5 \pm 0.3$ & $19.3 \pm 0.2$ & $192.7 \pm 1.4$ & $118.3 \pm 17.9$ \\
\hline & & & 15 & 2 & $55.3 \pm 7.9$ & $13.5 \pm 0.4$ & $18.4 \pm 0.6$ & $19.3 \pm 2.9$ & $193.0 \pm 3.5$ & $108.6 \pm 11.1$ \\
\hline & & & 25 & 2 & $50.5 \pm 3.1$ & $13.5 \pm 0.6$ & $18.8 \pm 0.6$ & $19.9 \pm 0.5$ & $192.4 \pm 2.9$ & $109.0 \pm 3.6$ \\
\hline & & \multirow{3}{*}{60} & 5 & 2 & $50.4 \pm 0.9$ & $13.2 \pm 0.4$ & $19.4 \pm 0.9$ & $20.0 \pm 0.5$ & $191.8 \pm 1.8$ & $107.2 \pm 9.9$ \\
\hline & & & 15 & 2 & $52.1 \pm 3.4$ & $13.5 \pm 0.2$ & $18.8 \pm 0.4$ & $20.9 \pm 1.1$ & $191.9 \pm 0.4$ & $116.7 \pm 8.0$ \\
\hline & & & 25 & 2 & $56.0 \pm 0.9$ & $13.7 \pm 0.3$ & $18.7 \pm 0.1$ & $19.7 \pm 0.8$ & $193.5 \pm 1.4$ & $122.4 \pm 9.2$ \\
\hline & \multirow{9}{*}{70} & & 5 & 2 & $50.2 \pm 2.9$ & $12.4 \pm 1.0$ & $21.2 \pm 0.2$ & $20.1 \pm 0.9$ & $185.7 \pm 7.1$ & $83.8 \pm 6.5$ \\
\hline & & 40 & 15 & 2 & $54.4 \pm 6.2$ & $13.3 \pm 1.1$ & $20.6 \pm 0.0$ & $21.2 \pm 0.2$ & $180.9 \pm 8.1$ & $93.8 \pm 7.5$ \\
\hline & & & 25 & 2 & $45.3 \pm 2.6$ & $13.3 \pm 1.5$ & $19.9 \pm 0.7$ & $20.3 \pm 0.4$ & $182.5 \pm 9.8$ & $87.9 \pm 8.0$ \\
\hline & & & 5 & 2 & $45.2 \pm 1.2$ & $13.5 \pm 0.3$ & $21.7 \pm 0.8$ & $19.0 \pm 3.0$ & $189.5 \pm 2.1$ & $82.7 \pm 7.6$ \\
\hline & & 50 & 15 & 2 & $58.4 \pm 13.0$ & $13.5 \pm 0.6$ & $21.6 \pm 1.2$ & $21.3 \pm 1.3$ & $190.7 \pm 5.2$ & $91.8 \pm 1.3$ \\
\hline & & & 25 & 2 & $57.2 \pm 10.3$ & $11.8 \pm 3.4$ & $21.7 \pm 0.2$ & $20.2 \pm 0.0$ & $188.3 \pm 3.2$ & $100.1 \pm 2.8$ \\
\hline & & & 5 & 2 & $49.5 \pm 0.5$ & $14.8 \pm 0.6$ & $22.5 \pm 1.1$ & $21.2 \pm 0.9$ & $190.0 \pm 2.0$ & $93.7 \pm 0.9$ \\
\hline & & 60 & 15 & 2 & $55.8 \pm 0.4$ & $14.7 \pm 0.4$ & $21.7 \pm 0.2$ & $21.5 \pm 1.0$ & $187.8 \pm 0.8$ & $90.8 \pm 5.8$ \\
\hline & & & 25 & 2 & $56.7 \pm 0.9$ & $13.0 \pm 0.4$ & $21.6 \pm 1.0$ & $22.6 \pm 0.6$ & $192.7 \pm 0.1$ & $103.7 \pm 1.8$ \\
\hline
\end{tabular}

The results are expressed as mean value \pm standard deviation $(N=2)$. TPC=total phenolic content, $T F=$ total flavonoids, TFLA=total flavonols, THC=total hydroxycinnamic acids, DPPH=2,2-diphenyl-1-picrylhydrazyl free radical scavenging capacity, FRAP=ferric reducing antioxidant power, $\mathrm{GAE}=$ gallic acid equivalents, $\mathrm{QE}=$ quercetin equivalents, $\mathrm{CAE}=$ caffeic acid equivalents, $\mathrm{TE}=\mathrm{Trolox}$ equivalents, $\mathrm{AAE}=$ ascorbic acid equivalents

Based on the presented results, aqueous ethanol solution was considered to be more effective solvent for extraction of the phenolic compounds than aqueous methanol solution. Higher antioxidant capacity from blackthorn flowers was also observed in aqueous ethanol. Furthermore, $70 \%$ aqueous solution of alcohol seems to be better solvent for the extraction of the phenolic compounds, al- though higher antioxidant capacity (DPPH and FRAP) was determined with $50 \%$ aqueous solutions.

\section{The influence of temperature and time}

Temperature is a factor that is interrelated with microwave power that controls the quantity of energy converted to heat in the dielectric material. Generally, higher 
Table 2. Influence of extraction parameters on the mass fractions of phenolic compounds and antioxidant capacity

\begin{tabular}{|c|c|c|c|c|c|c|c|}
\hline & $N$ & $w$ (TPC as GAE) & $w(\mathrm{TF}$ as $\mathrm{QE})$ & $w$ (TFLA as QE) & $w$ (THC as CAE) & DPPH (as TE) & FRAP (as AAE) \\
\hline & $N$ & $\mathrm{mg} / \mathrm{g}$ & $\mathrm{mg} / \mathrm{g}$ & $\mathrm{mg} / \mathrm{g}$ & $\mathrm{mg} / \mathrm{g}$ & $\mu \mathrm{mol} / \mathrm{g}$ & $\mathrm{mg} / \mathrm{g}$ \\
\hline Solvent type & & $\mathrm{p} \leq 0.01^{+}$ & $\mathrm{p} \leq 0.01^{+}$ & $\mathrm{p} \leq 0.01^{+}$ & $\mathrm{p}=0.77^{\ddagger}$ & $\mathrm{p}=0.65^{\ddagger}$ & $\mathrm{p}=0.02^{+}$ \\
\hline Ethanol & 36 & $(56.0 \pm 1.0)^{\mathrm{a}}$ & $(14.4 \pm 0.2)^{\mathrm{a}}$ & $(21.3 \pm 0.1)^{\mathrm{a}}$ & $(20.2 \pm 0.2)^{\mathrm{a}}$ & $(190.2 \pm 0.7)^{a}$ & $(94.5 \pm 2.1)^{\mathrm{a}}$ \\
\hline Methanol & 36 & $(52.2 \pm 1.0)^{\mathrm{b}}$ & $(13.3 \pm 0.2)^{\mathrm{b}}$ & $(20.0 \pm 0.1)^{\mathrm{b}}$ & $(20.1 \pm 0.2)^{\mathrm{a}}$ & $(190.6 \pm 0.7)^{a}$ & $(101.7 \pm 2.1)^{\mathrm{b}}$ \\
\hline$\overline{\varphi / \%}$ & & $\mathrm{p}=0.61^{\ddagger}$ & $\mathrm{p}=0.03^{+}$ & $\mathrm{p} \leq 0.01^{+}$ & $\mathrm{p} \leq 0.01^{+}$ & $\mathrm{p}=0.01^{+}$ & $\mathrm{p}=0.01^{+}$ \\
\hline 50 & 36 & $(53.7 \pm 1.0)^{\mathrm{a}}$ & $(13.6 \pm 0.2)^{\mathrm{a}}$ & $(19.4 \pm 0.1)^{a}$ & $(19.1 \pm 0.2)^{\mathrm{a}}$ & $(191.8 \pm 0.7)^{\mathrm{a}}$ & $(103.2 \pm 2.1)^{\mathrm{a}}$ \\
\hline 70 & 36 & $(54.4 \pm 1.0)^{\mathrm{a}}$ & $(14.1 \pm 0.2)^{\mathrm{b}}$ & $(21.9 \pm 0.1)^{\mathrm{b}}$ & $(21.3 \pm 0.2)^{\mathrm{b}}$ & $(188.9 \pm 0.7)^{\mathrm{b}}$ & $(93.0 \pm 2.1)^{\mathrm{b}}$ \\
\hline Temperature $/{ }^{\circ} \mathrm{C}$ & & $\mathrm{p}=0.01^{+}$ & $\mathrm{p}=0.02^{+}$ & $\mathrm{p} \leq 0.01^{+}$ & $\mathrm{p}=0.01^{+}$ & $\mathrm{p}=0.04^{+}$ & $\mathrm{p}=0.38^{\ddagger}$ \\
\hline 40 & 24 & $(51.1 \pm 1.2)^{a}$ & $(13.4 \pm 0.2)^{a}$ & $(20.2 \pm 0.2)^{a}$ & $(19.7 \pm 0.2)^{a}$ & $(188.5 \pm 0.9)^{a}$ & $(95.2 \pm 2.6)^{a}$ \\
\hline 50 & 24 & $(55.2 \pm 1.2)^{\mathrm{b}}$ & $(13.8 \pm 0.2)^{\mathrm{a} . \mathrm{b}}$ & $(20.5 \pm 0.2)^{a}$ & $(20.1 \pm 0.2)^{\text {a.b }}$ & $(191.0 \pm 0.9)^{\mathrm{a} . \mathrm{b}}$ & $(99.4 \pm 2.6)^{a}$ \\
\hline 60 & 24 & $(55.9 \pm 1.2)^{\mathrm{b}}$ & $(14.3 \pm 0.2)^{b}$ & $(21.2 \pm 0.2)^{\mathrm{b}}$ & $(20.7 \pm 0.2)^{\mathrm{b}}$ & $(191.7 \pm 0.9)^{\mathrm{b}}$ & $(99.7 \pm 2.6)^{a}$ \\
\hline$t / \mathrm{min}$ & & $\mathrm{p}=0.02^{+}$ & $\mathrm{p}=0.72^{\ddagger}$ & $\mathrm{p}=0.87^{\ddagger}$ & $\mathrm{p}=0.73^{\ddagger}$ & $\mathrm{p}=0.63^{\ddagger}$ & $\mathrm{p}=0.25^{\ddagger}$ \\
\hline 5 & 24 & $(51.3 \pm 1.2)^{a}$ & $(13.9 \pm 0.2)^{\mathrm{a}}$ & $(20.6 \pm 0.2)^{a}$ & $(20.1 \pm 0.2)^{\mathrm{a}}$ & $(190.5 \pm 0.9)^{\mathrm{a}}$ & $(94.6 \pm 2.6)^{a}$ \\
\hline 15 & 24 & $(56.0 \pm 1.2)^{\mathrm{b}}$ & $(13.7 \pm 0.2)^{\mathrm{a}}$ & $(20.7 \pm 0.2)^{a}$ & $(20.3 \pm 0.2)^{\mathrm{a}}$ & $(190.9 \pm 0.9)^{a}$ & $(99.2 \pm 2.6)^{\mathrm{a}}$ \\
\hline 25 & 24 & $(54.9 \pm 1.2)^{\mathrm{b}}$ & $(13.9 \pm 0.2)^{a}$ & $(20.6 \pm 0.2)^{a}$ & $(20.2 \pm 0.2)^{\mathrm{a}}$ & $(189.7 \pm 0.9)^{\mathrm{a}}$ & $(100.4 \pm 2.6)^{\mathrm{a}}$ \\
\hline$\varphi / \%$ & & $\mathrm{p}=0.95^{\ddagger}$ & $\mathrm{p}=0.18^{\ddagger}$ & $\mathrm{p}=0.06^{\ddagger}$ & $\mathrm{p} \leq 0.01^{+}$ & $\mathrm{p} \leq 0.01^{+}$ & $\mathrm{p} \leq 0.01^{+}$ \\
\hline Ethanol 50 & 18 & $(55.6 \pm 1.4)^{a}$ & $(14.0 \pm 0.2)^{\mathrm{a}}$ & $(20.2 \pm 0.2)^{a}$ & $(19.6 \pm 0.3)^{a}$ & $(190.0 \pm 1.0)^{a}$ & $(95.1 \pm 3.0)^{\mathrm{a}}$ \\
\hline Ethanol 70 & 18 & $(56.4 \pm 1.4)^{a}$ & $(14.9 \pm 0.2)^{a}$ & $(22.3 \pm 0.2)^{a}$ & $(20.8 \pm 0.3)^{\mathrm{b}}$ & $(190.3 \pm 1.0)^{\mathrm{a}}$ & $(93.9 \pm 3.0)^{\mathrm{a}}$ \\
\hline Methanol 50 & 18 & $(51.9 \pm 1.4)^{\mathrm{a}}$ & $(13.2 \pm 0.2)^{a}$ & $(18.6 \pm 0.2)^{a}$ & $(18.5 \pm 0.2)^{\mathrm{a}}$ & $(193.7 \pm 1.1)^{a}$ & $(111.3 \pm 3.0)^{a}$ \\
\hline Methanol 70 & 18 & $(52.5 \pm 1.4)^{\mathrm{a}}$ & $(13.4 \pm 0.2)^{\mathrm{a}}$ & $(21.4 \pm 0.2)^{\mathrm{a}}$ & $(21.8 \pm 0.2)^{\mathrm{b}}$ & $(187.6 \pm 1.1)^{\mathrm{b}}$ & $(92.0 \pm 3.0)^{\mathrm{b}}$ \\
\hline Grand mean* & 72 & 54.1 & 13.9 & 20.6 & 20.2 & 190.4 & 98.1 \\
\hline
\end{tabular}

The results are expressed as mean value \pm standard error of the mean. $t=$ the factor is significant in multifactor analysis, $\neq=$ the factor is not significant in multifactor analysis. Values with different letter in superscript within the same column are significantly different $(\mathrm{p}<0.05) .{ }^{*}$ Average amount of particular compound in the entire study.

TPC=total phenolic content, TF=total flavonoids, TFLA=total flavonols, THC=total hydroxycinnamic acids, DPPH=2,2-diphenyl-1-picrylhydrazyl free radical scavenging capacity, $\mathrm{FRAP}=$ ferric reducing antioxidant power

$\mathrm{GAE}=$ gallic acid equivalents, $\mathrm{QE}=$ quercetin equivalents, $\mathrm{CAE}=$ caffeic acid equivalents, $\mathrm{TE}=$ Trolox equivalents, $\mathrm{AAE}=\mathrm{ascorbic}$ acid equivalents

temperature enhances the extraction and reduces the reaction time, but if it is not selected properly it can also lead to degradation and thus impede the extraction yield $(24,46)$.

Based on the results presented in Table 2, it can be concluded that higher temperature exerted a significantly positive influence on the amounts of TF, THC and total flavonols extracted using MAE, which indicates that these phenolic compounds are relatively stable under higher temperature conditions. The highest amounts of TPC were obtained at between 50 and $60^{\circ} \mathrm{C}$. Higher temperature did not cause an increase only of FRAP values, while DPPH values show similar trend as other phenolic compounds. Similarly, Zhang et al. (47) reported that temperature of 60 ${ }^{\circ} \mathrm{C}$ was selected as the optimal one for isolation of chlorogenic acid from the flower buds of Lonicera japonica Thunb. by MAE.

The stability of phenolic compounds at higher temperatures $\left(50-60^{\circ} \mathrm{C}\right)$ can be related to the relatively short time of extraction (5-25 min). Selecting a proper extraction time is very important in order to enable completion of the extraction but also preservation and stability of phytochemicals in plants. In this study, the extraction time was set to 5,15 and $25 \mathrm{~min}$. The time of extraction had positive influence only on the amount of TPC $(p<0.05)$. The highest amounts of TPC were obtained in the 15- and 25-minute extraction. On the other hand, extending the time of extraction from 5 to $25 \mathrm{~min}$ did not seem to have a significant effect on the amounts of TF, total flavonols, THC, DPPH and FRAP ( $>>0.05$ ) of blackthorn flower extracts. This can be explained by the Fick's second law of diffusion, which predicts that there would be a final equilibrium between the solute in the plant sample (solid matrix) and the extraction solvent (bulk solution) after a certain time of extraction (48). Furthermore, overexposure in MAE may cause the loss of some phytochemicals. This was observed in the extraction of total phenolic acids from mandarin peels applying MAE, where extraction yield of some phytochemicals decreased with increasing extraction time, and thus 3 min was set as optimal time of extraction (49). Extended extraction time can cause undesirable reactions such as enzymatic degradation and oxidation and can result in decreased extraction yield of phenolic compounds (28). Thus, shorter extraction time, as one of major potential benefits of MAE, is favourable, as it reduces the risk of decomposition and oxidation of phytochemicals, and energy consumption (50). 


\section{Conclusions}

The results of this study indicate that solvent type influenced the extraction yield of almost all phenolic compounds, except those of the total hydroxycinnamic acids. Aqueous solution of ethanol was more appropriate solvent for the extraction of phenolic compounds from blackthorn flowers than aqueous solution of methanol. It was also observed that higher amount of phenolic compounds (total flavonoids, total hydroxycinnamic acids and total flavonols) was determined in $70 \%$ aqueous solution of alcohol (ethanol or methanol) than that in $50 \%$ aqueous solution of alcohol, while higher antioxidant capacity was observed in $50 \%$ aqueous solution of methanol. Additionally, the results indicate that the extraction efficiency of all phenols and DPPH values are better at a higher temperature. Higher temperature of extraction also improved the amount of phenolic compounds and DPPH, but it had no influence on FRAP. The extended duration of extraction (15-25 $\mathrm{min}$ ) has a significant effect only on the increase of TPC, while 5-minute extraction time was enough to complete the extraction of specific phenolic compounds and obtain maximum antioxidant capacity.

The obtained data could be very useful for identifying blackthorn flowers as a potential source of antioxidants, but further studies are required to give more precise evaluation of phenolic content and determine phenolic compounds responsible for the antioxidant capacity.

\section{Acknowledgements}

This research was supported by grants from the Croatian Science Foundation: Application of innovative technologies for production of plant extracts as ingredients for functional food (HRZZ 3035).

The authors are grateful for the donation of the plant material from Suban Ltd, Strmec, Croatia.

\section{References}

1. Pleše V. Blackthorn, black thorn (Prunus spinosa L.). Hrvatske šume. 2002;65:24-5 (in Croatian).

2. Popescu I, Caudullo G. Prunus spinosa in Europe: distribution, habitat, usage and threats. In: San-Miguel-Ayanz J, De Rigo D, Caudullo G, Houston Durrant T, Mauri A, editors. European atlas of forest tree species. Luxembourg, Luxembourg: Publication Office of the European Union; 2016. p. 145 .

3. Olszewska M, Wolbiś M. Flavonoids from the flowers of Prunus spinosa L. Acta Pol Pharm. 2001;58:367-72.

4. Olszewska M, Głowacki R, Wolbiś M, Bald E. Quantitative determination of flavonoids in the flowers and leaves of Prunus spinosa L. Acta Pol Pharm. 2001;58:199-203.

5. Tamas M. Study of flavones Prunus spinosa L. flowers. Farmacia. 1985;3:181-6.

6. Olszewska M, Wolbiś M. Phenolic acids in flowers and leaves of Prunus spinosa L. Herba Polon. 2000;46:249-54.

7. Kolodziej H, Sakar MK, Burger JFW, Engelshowe R, Ferreira D. A-type proanthocyanidins from Prunus spinosa. Phytochemistry. 1991;30:2041-7. https://doi.org/10.1016/0031-9422(91)85064-7

8. Sikora E, Bieniek MI, Borczak B. Composition and antioxidant properties of fresh and frozen stored blackthorn fruits
(Prunus spinosa L.). Acta Sci Pol Technol Aliment. 2013;12:365-72.

9. Bursać Kovačević D, Putnik P, Dragović-Uzelac V, Vahčić N, Skendrović Babojelić M, Levaj B. Influences of organically and conventionally grown strawberry cultivars on anthocyanins content and color in purees and low-sugar jams. Food Chem. 2015;181:94-100. https://doi.org/10.1016/j.foodchem.2015.02.063

10. Ajila CM, Brar SK, Verma M, Tyagi RD, Godbout S, Valéro JR. Extraction and analysis of polyphenols: recent trends. Crit Rev Biotechnol. 2011;31:227-49. https://doi.org/10.3109/07388551.2010.513677

11. Gupta A, Naraniwal M, Kothari V. Modern extraction methods for preparation of bioactive plant extracts. Int J Appl Nat Sci. 2012;1:8-26.

12. Putnik P, Bursać Kovačević D, Radojčin M, Dragović-Uzelac $\mathrm{V}$. Influence of acidity and extraction time on the recovery of flavonoids from grape skin pomace optimized by response surface methodology. Chem Biochem Eng Q. 2016;30:455-64. https://doi.org/10.15255/CABEQ.2016.914

13. Putnik P, Bursać Kovačević D, Dragović-Uzelac V. Optimizing acidity and extraction time for polyphenolic recovery and antioxidant capacity in grape pomace skin extracts with response surface methodology approach. J Food Process Preserv. 2016;40:1256-63.

https://doi.org/10.1111/jfpp.12710

14. Bursać Kovačević D, Gajdoš Kljusurić J, Putnik P, Vukušić T, Herceg Z, Dragović-Uzelac V. Stability of polyphenols in chokeberry juice treated with gas phase plasma. Food Chem. 2016;212:323-31.

https://doi.org/10.1016/j.foodchem.2016.05.192

15. Bursać Kovačević D, Putnik P, Dragović-Uzelac V, Pedisić S, Režek Jambrak A, Herceg Z. Effects of cold atmospheric gas phase plasma on anthocyanins and color in pomegranate juice. Food Chem. 2016;190:317-23.

https://doi.org/10.1016/j.foodchem.2015.05.099

16. Bursać Kovačević D, Putnik P, Pedisić S, Ježek D, Karlović S, Dragović-Uzelac V. High hydrostatic pressure extraction of flavonoids from freeze-dried red grape skin as winemaking by-product. Ann Nutr Metab. 2015;67(Suppl 1):521-2. https://doi.org/10.1159/000440895

17. Dragović-Uzelac V, Putnik P, Zorić Z, Ježek D, Karlović S, Bursać Kovačević D. Winery by-products: anthocyanins recovery from red grape skin by high hydrostatic pressure extraction (HHPE). Ann Nutr Metab. 2015;67(Suppl 1):522-3. https://doi.org/10.1159/000440895

18. Plazibat V, Bursać Kovačević D, Putnik P, Jukić M, Tranfić Bakić M, Dragović-Uzelac V. The effect of microwave assisted extraction (MAE) on the isolation of polyphenols from hawthorn. Ann Nutr Metab. 2015;67(Suppl 1):527-8. https://doi.org/10.1159/000440895

19. Putnik P, Bursać Kovačević D, Penić M, Fegeš M, DragovićUzelac V. Microwave-assisted extraction (MAE) of Dalmatian sage leafs for the optimal yield of polyphenols: HPLC-DAD identification and quantification. Food Anal Methods. 2016;9:2385-94.

https://doi.org/10.1007/s12161-016-0428-3

20. Putnik P, Bursać Kovačević D, Penić M, Dragović-Uzelac V. Optimizing microwave-assisted extraction parameters for polyphenols recovery from sage (Salvia officinalis L.). Ann Nutr Metab. 2015;67(Suppl 1):523-4. https://doi.org/10.1159/000440895

21. Elez Garofulić I, Dragović-Uzelac V, Režek Jambrak A, Jukić $M$. The effect of microwave assisted extraction on the isolation of anthocyanins and phenolic acids from sour cherry Marasca (Prunus cerasus var. Marasca). J Food Eng. 2013;117:437-42.

https://doi.org/10.1016/j.jfoodeng.2012.12.043 
22. Zhu X, Su Q, Cai J, Yang J. Optimization of microwave assisted solvent extraction for volatile organic acids in tobacco and its comparison with conventional extraction methods. Anal Chim Acta. 2006;579:88-94. https://doi.org/10.1016/j.aca.2006.07.005

23. Dai J, Mumper RJ. Plant phenolics: extraction, analysis and their antioxidant and anticancer properties. Molecules. 2010;15:7313-52.

https://doi.org/10.3390/molecules15107313

24. Dragović-Uzelac V, Elez Garofulić I, Jukić M, Penić M, Dent $\mathrm{M}$. The influence of microwave-assisted extraction on the isolation of sage (Salvia officinalis L.) polyphenols. Food Technol Biotechnol. 2012;50:377-83.

25. Veggi PC, Martinez J, Meireles MAA. Fundamentals of microwave extraction. In: Chemat F, Cravotto G, editors. Food engineering series, vol 4. Microwave-assisted extraction for bioactive compounds: theory and practice. New York, NY, USA: Springer Science+Business Media; 2013. pp.15-52. https://doi.org/10.1007/978-1-4614-4830-3_2

26. Afoakwah N, Owusu J, Adomako C, Teye E. Microwave assisted extraction (MAE) of antioxidant constituents in plant materials. Glob J Bio-Science Biotechnol. 2012;1:132-40.

27. Jain T, Jain V, Pandey R, Vyas A, Shukla SS. Microwave assisted extraction for phytoconstituents - an overview. Asian J Research Chem. 2009;2:19-25.

28. Khoddami A, Wilkes MA, Roberts TH. Techniques for analysis of plant phenolic compounds. Molecules. 2013;18:232875. https://doi.org/10.3390/molecules18022328

29. Wang L, Weller CL. Recent advances in extraction of nutraceuticals from plants. Trends Food Sci Techol. 2006;17:30012.

https://doi.org/10.1016/j.tifs.2005.12.004

30. Eskilsson CS, Björklund E. Analytical-scale microwave-assisted extraction. J Chromatogr A. 2000;902:227-50. https://doi.org/10.1016/S0021-9673(00)00921-3

31. Shortle E, O'Grady MN, Gilroy D, Furey A, Quinn N, Kerry JP. Influence of extraction technique on the anti-oxidative potential of hawthorn (Crataegus monogyna) extracts in bovine muscle homogenates. Meat Sci. 2014;98:828-34. https://doi.org/10.1016/j.meatsci.2014.07.001

32. Chang CC, Yang MH, Wen HM, Chern JC. Estimation of total flavonoid in propolis by two complementary colorimetric methods. J Food Drug Anal. 2002;10:178-82.

33. Howard LR, Clark JR, Brownmiller C. Antioxidant capacity and phenolic content in blueberries as affected by genotype and growing season. J Sci Food Agr. 2003;83:1238-47. https://doi.org/10.1002/jsfa.1532

34. Nuengchamnong N, Krittasilp K, Ingkaninan K. Rapid screening and identification of antioxidants in aqueous extracts of Houttuynia cordata using LC-ESI-MS coupled with DPPH assay. Food Chem. 2009;117:750-6. https://doi.org/10.1016/j.foodchem.2009.04.071

35. Fegredo JA, Wong MCY, Wiseman H, Preedy VR. Manual and robotic methods for measuring the total antioxidant capacity of beers. In: Preedy VR, editor. Beer in health and disease prevention. San Diego, CA, USA: Academic Press; 2009. pp. 991-1002.

36. IBM SPSS, v. 20.0, IBM Corp, Armonk, NY, USA; 2011. Available from: https://www.ibm.com.
37. Statgraphics Centurion, v. 17, StatPoint Technologies, Inc, Warrenton, VA, USA; 2015. Available from: http://www.statgraphics.com.

38. Olszewska M, Kwapisz A. Metabolite profiling and antioxidant properties of Prunus padus L. flowers and leaves. Nat Prod Res. 2011;25:1115-31. https://doi.org/10.1080/14786410903230359

39. Ince AE, Sahin S, Sumnu G. Comparison of microwave and ultrasound-assisted extraction techniques for leaching of phenolic compounds from nettle. J Food Sci Techol. 2014;51:2776-82. https://doi.org/10.1007/s13197-012-0828-3

40. Wang H, Helliwell K. Determination of flavonols in green and black tea leaves and green tea infusions by high-performance liquid chromatography. Food Res Int. 2001;34:223-7. https://doi.org/10.1016/S0963-9969(00)00156-3

41. Drużyńska B, Stępniewska A, Wołosiak R. The influence of time and type of solvent on efficiency of the extraction of polyphenols from green tea and antioxidant properties obtained extracts. Acta Sci Pol Technol Aliment. 2007;6:27-36.

42. Song J, Li D, Liu C, Zhang Y. Optimized microwave-assisted extraction of total phenolics (TP) from Ipomoea batatas leaves and its antioxidant properties. Innov Food Sci Emerg. 2011;12:282-7. https://doi.org/10.1016/j.ifset.2011.03.001

43. Zhang ZS, Li D, Wang LJ, Ozkan N, Chen XD, Mao ZH, Yang HZ. Optimization of ethanol-water extraction of lignans from flaxseed. Sep Purif Technol. 2007;57:17-24. https://doi.org/10.1016/j.seppur.2007.03.006

44. Thoo YY, Ng SY, Khoo MZ, Wan Aida WM, Ho CW. A binary solvent extraction system for phenolic antioxidants and its application to the estimation of antioxidant capacity in Andrographis paniculata extracts. Int Food Res J. 2013;20:110311.

45. Yu L, Haley S, Perret J, Harris M, Wilson J, Qian M. Free radical scavenging properties of wheat extracts. J Agric Food Chem. 2002;50:1619-24. https://doi.org/10.1021/jf010964p

46. Yan MM, Liu W, Fu YJ, Zu YG, Chen CY, Luo M. Optimisation of the microwave-assisted extraction process for four main astragalosides in Radix Astragali. Food Chem. 2010;119:1663-70.

https://doi.org/10.1016/j.foodchem.2009.09.021

47. Zhang B, Yang R, Liu CZ. Microwave-assisted extraction of chlorogenic acid from flower buds of Lonicera japonica Thunb. Sep Purif Technol. 2008;62:480-3. https://doi.org/10.1016/j.seppur.2008.02.013

48. Chew KK, Khoo MZ, Ng SY, Thoo YY, Wan Aida MW, Ho CW. Effect of ethanol concentration, extraction time and extraction temperature on the recovery of phenolic compounds and antioxidant capacity of Orthosiphon stamineus extracts. Int Food Res J. 2011;18:1427-35.

49. Ahmad J, Langrish TAG. Optimizations of total phenolic acids extraction from mandarin peels using microwave energy: the importance of the Maillard reaction. J Food Eng. 2012;109:162-74.

https://doi.org/10.1016/j.jfoodeng.2011.09.017

50. Uttara J, Ware L, Mohini U. Microwave assisted extraction of crude drugs. Int J Pharm Bio Sci. 2010;1:330-2. 